\title{
Impact of photoisomerization on the one-dimensional fluid and three- dimensional Abrikosov-like photonic structures of liquid crystals
}

Rajalaxmi Sahoo, ${ }^{\mathrm{a}, \mathrm{b}}$, D.S. Shankar Rao ${ }^{\mathrm{a},{ }^{*}}$, U.S. Hiremath, ${ }^{\mathrm{a}}$ C.V. Yelamaggad ${ }^{\mathrm{a}}$, S. Krishna Prasad $^{\mathrm{a}}$

${ }^{a}$ Centre for Nano and Soft Matter Sciences, Bengaluru 560013, India

${ }^{b}$ Manipal Academy of Higher Education (MAHE), Manipal 576104, India

*email: raoshankards@gmail.com

\section{Supporting Information Description}

1) Figure S1: Absorbance spectra obtained in the cholesteric phase of mixture 1 before and after exposing to UV radiation

2) Figure S2: POM picture showing simultaneous regions of $\mathrm{Ch}$ and $\mathrm{TGBC}^{*}$ texture with UV exposed and unexposed regions respectively. 


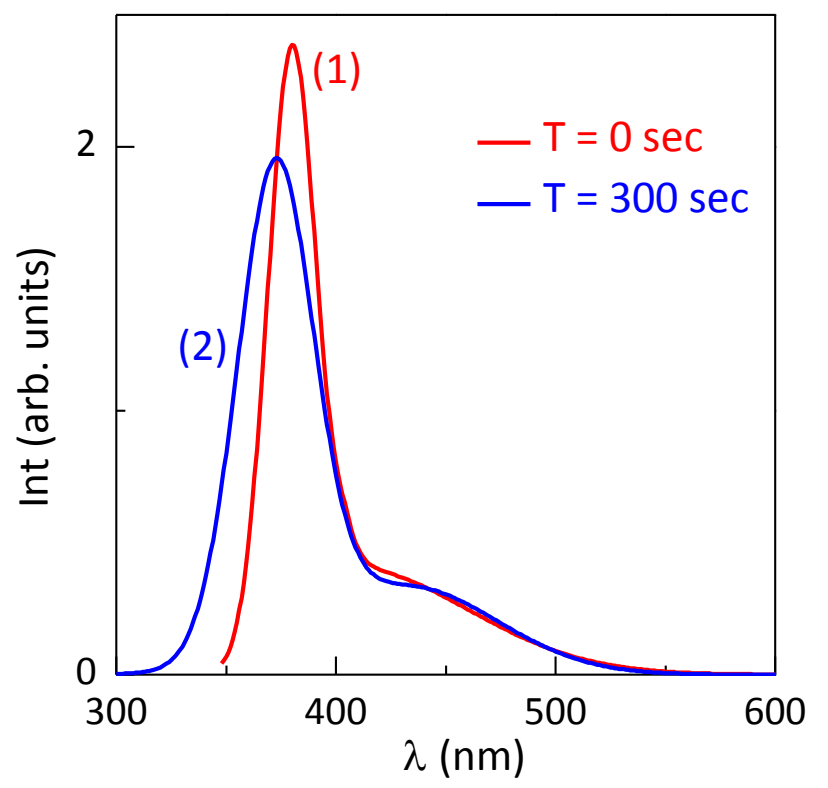

Figure S1: Absorbance spectra obtained in the cholesteric phase of mixture 1 before (curve (1)) and after (curve (2) exposing to a $365 \mathrm{~nm}$ UV radiation of $1.1 \mathrm{~mW} / \mathrm{cm}^{2}$ at $\mathrm{T}_{\text {red } 1}=-1.5^{\circ} \mathrm{C}$. The decrease in the absorbance value at $365 \mathrm{~nm}$ after irradiation is due to the trans-cis photoisomerization. 


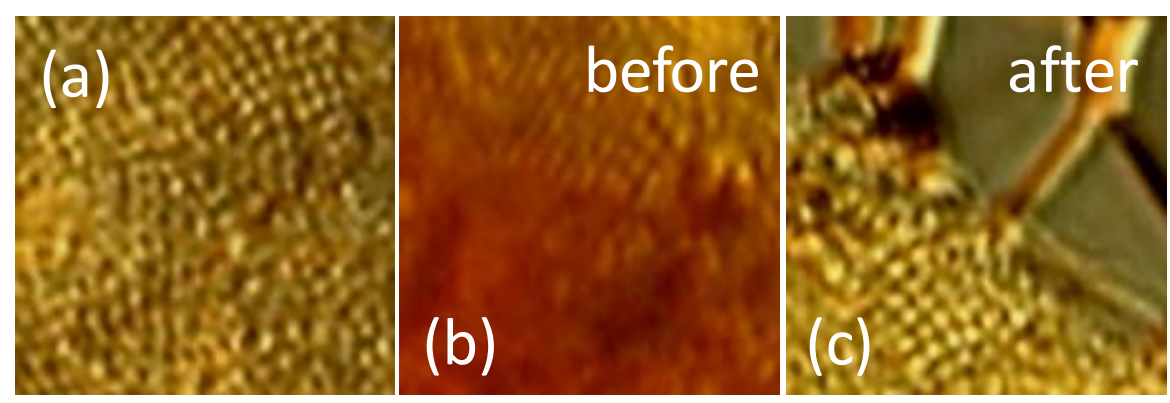

Figure S2: POM picture showing texture in the (a) TGBC* phase, (b) with a mask covering half of the region before UV on and (c) showing simultaneous regions of $\mathrm{Ch}$ and $\mathrm{TGBC}^{*}$ texture with UV exposed and unexposed regions respectively. 